\title{
The perspectives of men in Mexico City about vasectomy
}

Isabel Vieitez Martínez

Population Council

Adriana Ramos

Population Council

Follow this and additional works at: https://knowledgecommons.popcouncil.org/departments_sbsr-rh

Part of the Demography, Population, and Ecology Commons, Family, Life Course, and Society Commons, International Public Health Commons, and the Reproductive and Urinary Physiology Commons How does access to this work benefit you? Let us know!

\section{Recommended Citation}

Martínez, Isabel Vieitez and Adriana Ramos. 2018. "The perspectives of men in Mexico City about vasectomy." Mexico City: Population Council. 


\section{THE PERSPECTIVES OF MEN IN MEXICO CITY ABOUT VASECTOMY}





\section{TABLE OF CONTENTS}

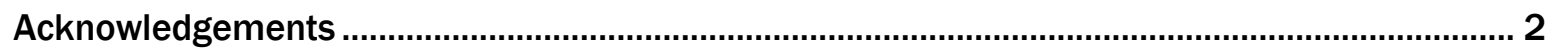

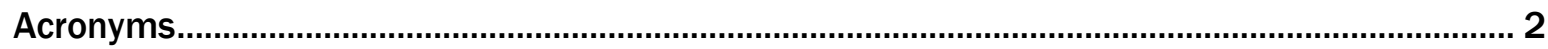

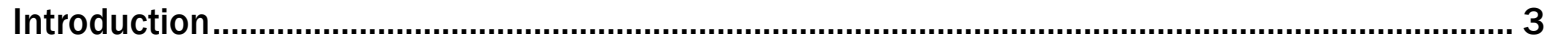

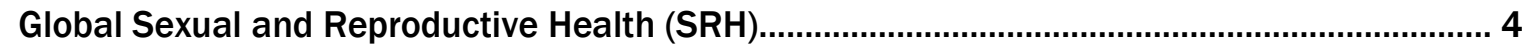

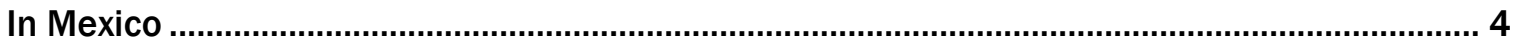

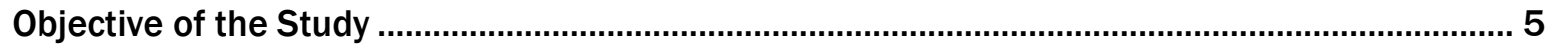

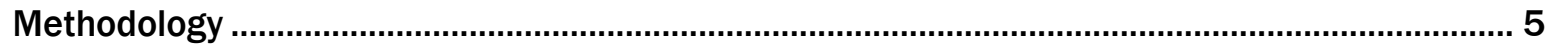

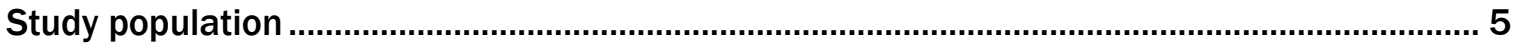

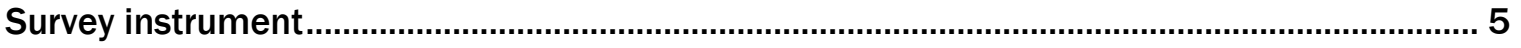

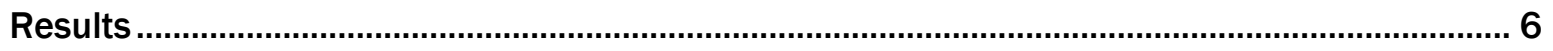

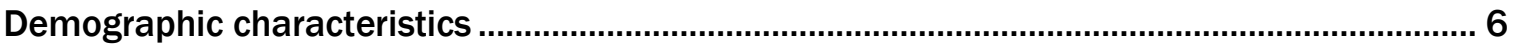

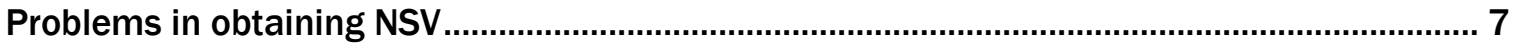

With whom did you confer prior to the procedure?

Method of contraception or family planning used most frequently ........................................ 7

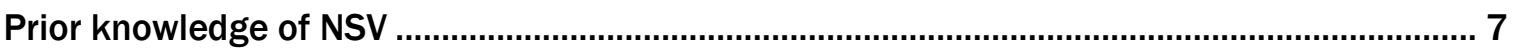

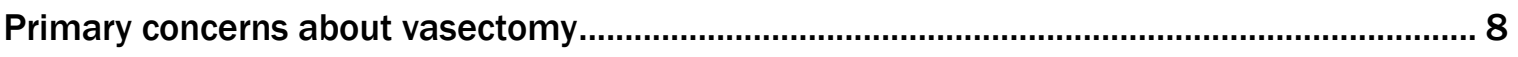

Benefits expected to obtain in your relationship after NSV .................................................. 9

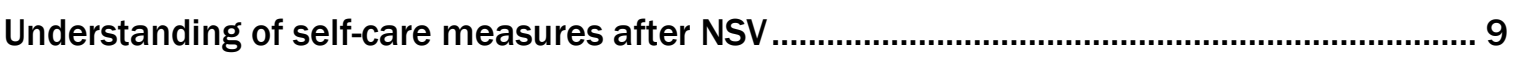

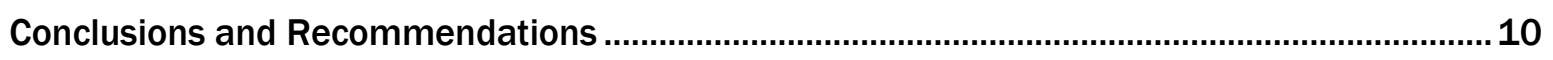

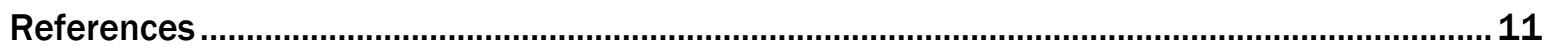




\section{ACKNOWLEDGEMENTS}

National Center for Gender Equity and Reproductive Health (CNEGySR): Rufino Luna and Yolanda Varela Ministry of Health of Mexico City (SEDESA): Patricio Sanhueza Smith

DKT Mexico: Luis Arturo Cruz Fernández

Population Council Mexico: Isabel Vieitez and Adriana Ramos

...for their support in the research, development, writing, and production of the report, and all accompanying materials.

We thank the World Vasectomy Day for their support and interest in the development of this study.

\section{LIST OF ACRONYMS}

$\begin{array}{ll}\text { CNEGySR } & \text { National Center for Gender Equity and Reproductive Health } \\ \text { ENADID } & \text { National Survey of Demographic Dynamics } \\ \text { FP } & \text { Family Planning } \\ \text { IMSS } & \text { Mexican Institute of Social Security } \\ \text { ISSSTE } & \text { Institute of Security and Social Services of State Workers } \\ \text { NSV } & \text { No-Scalpel Vasectomy } \\ \text { SEDESA } & \text { Ministry of Health of Mexico City } \\ \text { SRHR } & \text { Sexual and Reproductive Health and Rights } \\ \text { SSA } & \text { Ministry of Health of Mexico } \\ \text { STI } & \text { Sexually Transmitted Infection } \\ \text { WVD } & \text { World Vasectomy Day }\end{array}$




\section{INTRODUCTION}

On 17 November 2017, Mexico City took part in the World Vasectomy Day (WVD) ${ }^{1}$ global campaign ${ }^{2}$ to promote male participation in family planning (FP), particularly no-scalpel vasectomy (NSV) ${ }^{3}$. This event is part of efforts in recent years to promote free vasectomy services throughout Mexico and the world. Mexico partnered with WVD first in 2016, and in 2017 was selected as the official venue due to the country's efforts in promoting free vasectomy services. NSV was incorporated in Mexico's FP Program in 1993. Currently the National FP Program is coordinated by the Ministry of Health (SSA, for its acronym in Spanish), through the National Center for Gender Equity and Reproductive Health (CNEGSR).

WVD in 2017 involved intense promotion, diffusion, and service provision in the 32 states of the country, by SSA and other public health institutions such as the Mexican Institute of Social Security (IMSS) and Institute of Security and Social Services of State Workers (ISSSTE). In Mexico City, activities were in coordination with the City's Ministry of Health (SEDESA) and DKT Mexico, a non-profit organization that promotes sexual and reproductive health (SRH), FP, and the prevention of sexually transmitted infections (STIs). DKT's experience and participation, with creative designs and innovative communication strategies, was fundamental to WVD's success.

A press conference began the event in Mexico City, with SSA authorities such as Dr. Rufino Luna, Deputy Director General of RH for CNEGSR; Dr. Patricio Sanhueza, RH Coordinator for SEDESA CDMX, John Townsend, Director of Country Strategy for the Population Council, Ana Karina de la Vega, Director of DKT Mexico, and Jonathan Stack, leader WVD. NSVs were performed in various clinics and mobile units of SSA, IMSS, ISSSTE, and DKT throughout the country during the event.

SSA held intensive vasectomy days in 261 clinics. In Mexico City, SEDESA's Dr. Manuel Escontría Health Center was the headquarters of the WVD "Vasectomy-athon," where global activity was coordinated for 24 hours. The health center performed NSVs from 8:00 am to 10:00 pm for two consecutive days.

On 19 November, with the participation of different civil society organizations working in SRH, a large event at the Monumento a la Revolución, which included a wrestling match, concerts, and public acknowledgment of doctors and men who took part in WVD. Mobile units ${ }^{4}$ provided NSV procedures and other interventions such as counseling on contraceptive methods, health, and HIV and STI prevention.

As a result of this series of events, 6,477 vasectomies 5 were performed in the country, and an estimated 15,000 worldwide (WVD Report 2017).

1 Vasectomy is a surgical procedure for male sterilization or permanent contraception. During the procedure, the male vas deferens are cut and tied to prevent sperm from entering the urethra and prevent fertilization. It is a safe and effective method, adopted by Mexico's SSA FP Program (Secretaría de Salud 2016).

2 The event was established in 2013 and since then has had a host country from which activities are disseminated to 60 countries; former host countries are Kenya, Indonesia, the United States, and Australia.

3 Compared to the regular procedure, NSV utilizes a single puncture to the scrotum and requires no suturing or stitches. It is a less painful procedure with fewer postoperative complications (Secretaría de Salud 2016).

4119 NSVs were performed by DKT mobile units.

5 In Mexico, between 16 October and 19 November 2017

6 For more information: www.worldvasectomyday.org 


\section{Global Sexual and Reproductive Health}

Since the 1990s, there has been significant progress worldwide in the promotion of sexual and reproductive health and rights (SRHR). The 1994 International Conference on Population and Development in Cairo articulated and emphasized the importance of male FP and SRHR participation. Vasectomy is one of three contraceptive methods available to men; withdrawal and the condom constitute the other two. Fertility awareness methods engage men, but the practice is really focused on the couple.

Unfortunately, great disparity is observed between developed and developing countries for male sterilization. The prevalence of vasectomy in the United States and Canada is 12 percent, and in Oceania and Northern Europe it is 11 percent, but it differs widely in developing countries, with a prevalence of less than one percent in Africa (Jacobstein 2015).

\section{In Mexico}

In accordance with international recommendations to include men in FP and SRH, Mexico's current FP Program (2013-2018) has emphasized men's participation in the FP and contraceptive decision-making process. Public FP services have provided in Mexico for 40 years, but despite recent efforts to encourage male FP participation, only 0.2 out of 10 female contraceptive users report vasectomy as a controlled method, according to the National Survey of Demographic Dynamics 2014 (ENADID); 84 percent of male respondents reported condom use during their first sexual intercourse.

From 2012 to 2016, more than 538,000 vasectomies were performed in Mexican public health institutions (SSA 2016). IMSS-Prospera ${ }^{7}$ and SSA, among all national public health institutions, show the highest increases in men's acceptance of permanent FP methods. Men's FP participation, compared with women's, continues to be quite low (SSA 2013). According to figures from the United Nations (UN), in 2015 Mexico reported 32.9 percent of the country's women having adopted a surgical method (sterilization), with only 1.2 percent of men having had a vasectomy (UN 2017).

In 2016 CNEGSR reported 41,045 vasectomies performed in Mexico among men ages 20 to 64, revealing ample opportunity for increased men's access to this safe, effective, and reliable procedure. According to SEDESA, during the present administration (2012-2018) 4,288 vasectomies have been performed in Mexico City, in contrast to 40,277 tubal ligations; for every 10 women undergoing female sterilization, only one vasectomy was performed (Excelsior 2017).

In general, only 18 percent of men reported participating in the FP (and SRH) decision-making process (ENADID). This is in accordance with Marvin et al. (2017), which explains low male FP participation as resulting from social norms, with contraception traditionally assumed as a woman's responsibility.

In several Latin American countries, generally men who choose vasectomy are older than 30, with three or fewer children, in urban areas, having used contraception prior to the vasectomy, and with greater than average schooling (Pile et al. 2009). In Mexico there is a positive correlation between a male's decision of vasectomy and his level of education and income (Malagón et al. 2011).

Several 'myths' or misconceptions about vasectomy are undoubtedly contributing to men's reluctance to utilize the procedure, including purported negative health effects including urination difficulties, semen accumulation in the body, increase or loss of weight (Bunce et al. 2007), and negative effects on sexual performance. In rural Mexico, some men report that vasectomy could adversely affect their masculine image in addition to extramarital sexual relations (García Moreno and Solano Sainos 2005).

7 Prospera is a government social assistance program in Mexico. 


\section{STUDY OBJECTIVE}

As part of WVD, Population Council Mexico conducted an exploratory study about the reasons and concerns that led men to seek a NSV during the 24-hour "Vasectomy-athon" in Mexico City. This study was intended as the first part of a longer cohort study that would follow up with the men, and their partners, to learn about their experiences with the procedure and its effects, if any, on their relationships.

\section{METHODOLOGY}

A pre-post study in the T-III Health Center Dr. Manuel Escontría and in mobile units of SEDESA and DKT at the Monumento a la Revolución involved 116 men who elected to have NSV. The survey, collected by DKT staff, included questions on reasons for, prior knowledge of, and concerns about NSV collected prior to the procedure, in addition to their understanding of post-surgical care measures collected immediately after the procedure and their surgical care indications and instructions.

\section{Study Population}

A convenience sample of men over 18 years of age was constituted by men who agreed to participate in the survey while waiting for their NSV during WVD. Participants signed an informed consent form, within which the purpose of the survey was clearly stipulated: to improve information in Mexico on SRH and obtain evidence of how men and their partners decided to accept NSV. In addition, the informed consent requested authorization to contact the interviewee, at both three and six months after the NSV, to perform a sperm count and evaluate the procedure's outcome. At the end of the NSV, respondents received postsurgical care instructions and then answered a short questionnaire assessing their knowledge of antiseptic measures, fertility monitoring, and STI prevention.

The analytical sample comprised 116 men who responded to a survey in total, in both locations ${ }^{8}$.

\section{Survey Instrument}

The survey included 25 questions, including eight for socio-demographic information, with the rest on males' reasons, fears, and expectations about NSV, as well as questions on post-surgical care and measures to prevent unwanted pregnancy and STIs. The questionnaire included multiple choice questions on reasons to perform a vasectomy, primary concerns, prior searches for NSV services and reasons why they had not already had the procedure, with whom they discussed the procedure and if anyone recommended it, prior knowledge of NSV (with multiple answers testing if their knowledge was correct ${ }^{9}$ or incorrect ${ }^{10}$ ), contraception used most frequently prior to NSV, and expected benefits and understanding of post-surgical care.

\footnotetext{
8 Analysis used both location populations, since there were no significant differences $(p<0.05)$ in socio-demographic characteristics.

9 It included that NSV is a simple procedure, an effective and permanent contraceptive method, no general anesthesia is needed, low risk procedure, no changes in sexual performance.

10 It included erroneous message: less effective than tubal ligation, requires hospitalization, and $100 \%$ reversible.
} 


\section{RESULTS}

\section{Demographic characteristics}

Among the respondents ${ }^{11}, 11.2$ percent were young males under 25 years of age, 75.9 percent were between 25 and 44, and 12.9 percent were 45 or older. Most reported being married or in a stable relationship (82.6\%), or single (16.5\%), with few divorced (0.9\%). Number of children ranged from zero to six, with the highest proportion for one to three children (74.2\%). It is noteworthy that 17.2 percent of respondents reported no children at the time of the procedure. Four out of five men (83.5\%) reported more than secondary educations, with 43.5 percent with higher education and 4.3 percent with postgraduate study; only 14.8 percent reported education under national average. ${ }^{12}$ When asked who accompanied them for the NSV, 73.1 percent were accompanied by a relative, 37.4 percent came alone, and seven percent came with a friend ${ }^{13}$.

\section{Table 1. Demographic characteristics of men who chose NSV}

\begin{tabular}{|c|c|c|c|}
\hline & & $\mathrm{N}$ & $\%$ \\
\hline \multicolumn{2}{|c|}{ Total } & 116 & 100 \\
\hline \multirow[t]{3}{*}{ Age group } & $19-24$ & 13 & 11.2 \\
\hline & $25-44$ & 88 & 75.9 \\
\hline & $45-60$ & 15 & 12.9 \\
\hline \multirow[t]{7}{*}{ Education } & No education & 1 & 0.9 \\
\hline & Primary & 3 & 2.6 \\
\hline & Secondary & 13 & 11.3 \\
\hline & Tertiary & 41 & 35.7 \\
\hline & Higher education & 50 & 43.5 \\
\hline & Postgraduate Studies & 5 & 4.3 \\
\hline & Other & 2 & 1.7 \\
\hline \multirow[t]{4}{*}{ Marital Status } & Married & 70 & 60.9 \\
\hline & Single & 19 & 16.5 \\
\hline & Stable relationship & 25 & 21.7 \\
\hline & Divorce & 1 & 0.9 \\
\hline \multirow[t]{4}{*}{ Accompanied by } & Friends & 8 & 7 \\
\hline & No one & 43 & 37.4 \\
\hline & Other & 44 & 38.3 \\
\hline & Relatives & 20 & 17.4 \\
\hline \multirow[t]{7}{*}{ Number of children } & 0 & 20 & 17.2 \\
\hline & 1 & 14 & 12.1 \\
\hline & 2 & 51 & 44 \\
\hline & 3 & 21 & 18.1 \\
\hline & 4 & 6 & 5.2 \\
\hline & 5 & 3 & 2.6 \\
\hline & 6 & 1 & 0.9 \\
\hline \multirow[t]{2}{*}{ Place } & $\begin{array}{l}\text { "Manuel Escontría" Health } \\
\text { Center }\end{array}$ & 45 & 38.5 \\
\hline & "Monumento a la Revolución" & 72 & 61.5 \\
\hline
\end{tabular}

11 One case did not report demographic information.

12 There was only one person in the sample who reported not having any education.

13 Participants could mention more than one person accompanying them to the procedure. 


\section{Problems in obtaining NSV}

One third (33.5\%) of respondents had tried to obtain NSV prior to the event. Among those, most were 19 to 24 years old $(61.5 \%)$, who sought the service in public $(74.5 \%)$ or private hospitals (37.5\%). Many of these men reported not having any children, and some commented that they were denied NSV services after counseling for this reason ${ }^{14}$. Respondents stated that lack of time or long wait times, and lack of personnel and bureaucratic issues at public hospitals (80.5\%) caused their failure to obtain a vasectomy, while 29.3 percent identified cost.

\section{With whom did you confer prior to the procedure?}

This variable was calculated based on the 60 cases who knew someone who had undergone NSV and the 67 cases who answered the question. Most respondents-77.6 percent $(n=90)$-talked with a stable partner about the procedure, while 10.3 percent reported not having talked with anyone about it. In addition, of the men who consulted with a doctor, 95.7 percent $(n=111)$ reported going to a gynecologist. When asked if any member of their family, friend, or acquaintance had undergone NSV, 52.6 percent answered affirmatively, and 31.7 percent responded that it was the same person who recommended the procedure.

\section{Method of contraception or family planning used most frequently}

The male condom was the most frequently used method in all age groups (66.4\%), followed by long-term reversible contraceptive methods (LARCs) (19.8\%), with contraceptive pills and withdrawal both at the same percentage (8.6\%). No contraception was reported by 9.5 percent of participants. Tubal ligation (3.4\%) and female diaphragm (2.6\%) were the least-used contraceptive methods. Condoms were more used among 45 to 60 year olds, while LARCs are used mostly by young adults (23.1\%), followed by withdrawal $(15.4 \%)^{15}$.

\section{Previous knowledge of NSV}

Most interviewed males (73.3\%) evinced correct knowledge of the NSV procedure, with only 14.7 percent revealing any misconceptions. In deliberating about this contraceptive option, men searched for information about NSV on social networks (40.5\%), from health care personnel (26.7\%), and through mass media such as television, radio, magazines, or newspapers (24.1\%). Most (61.5\%) 19 to 24 year old males obtained information about the procedure through social media.

\section{Primary reasons for choosing NSV}

The most important reported reason for NSV was to avoid unwanted pregnancy (58.6\%), followed by the desire to support a partner in FP (17.2\%), along with problems with partner's health or genetic incompatibility (11.2\%); the latter was more frequently mentioned among older males. The "other" category, including environmental or social awareness issues, was mentioned by the 19 to 24 age group, with some reporting having no children (see Figure 1). No differences were statistically significant.

\footnotetext{
14 Field journal notes

15 Participants could mention more than one method.
} 
Figure 1. Primary reasons for choosing NSV

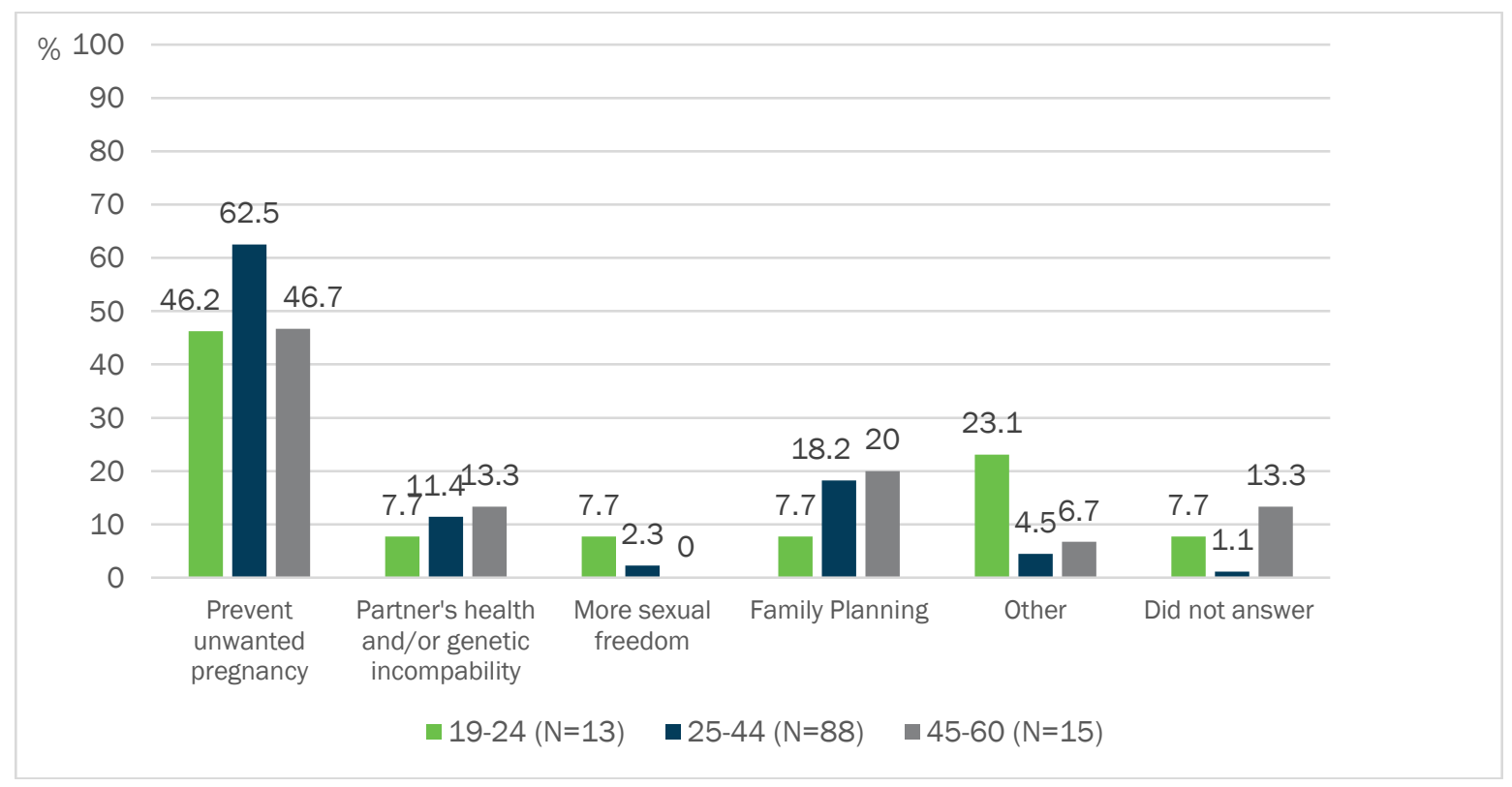

\section{Primary concerns about vasectomy}

Potential complications from the procedure, due to anesthesia or resultant pain, were the primary concerns for all age groups (45.7\%) (Figure 2). There were no significant statistical differences between age groups ( $p>0.05)$. One third (32.8\%) of respondents reported no fear, while 10.3 percent reported fear of negative effects on their sexual performance or masculinity. Concerns about masculinity were not mentioned by the 19 to 24 year old group, but this group did report fears about medical complications as well as concerns about reduced sexual activity after NSV. None of the differences were statistically significant.

Figure 2. Primary concerns about vasectomy

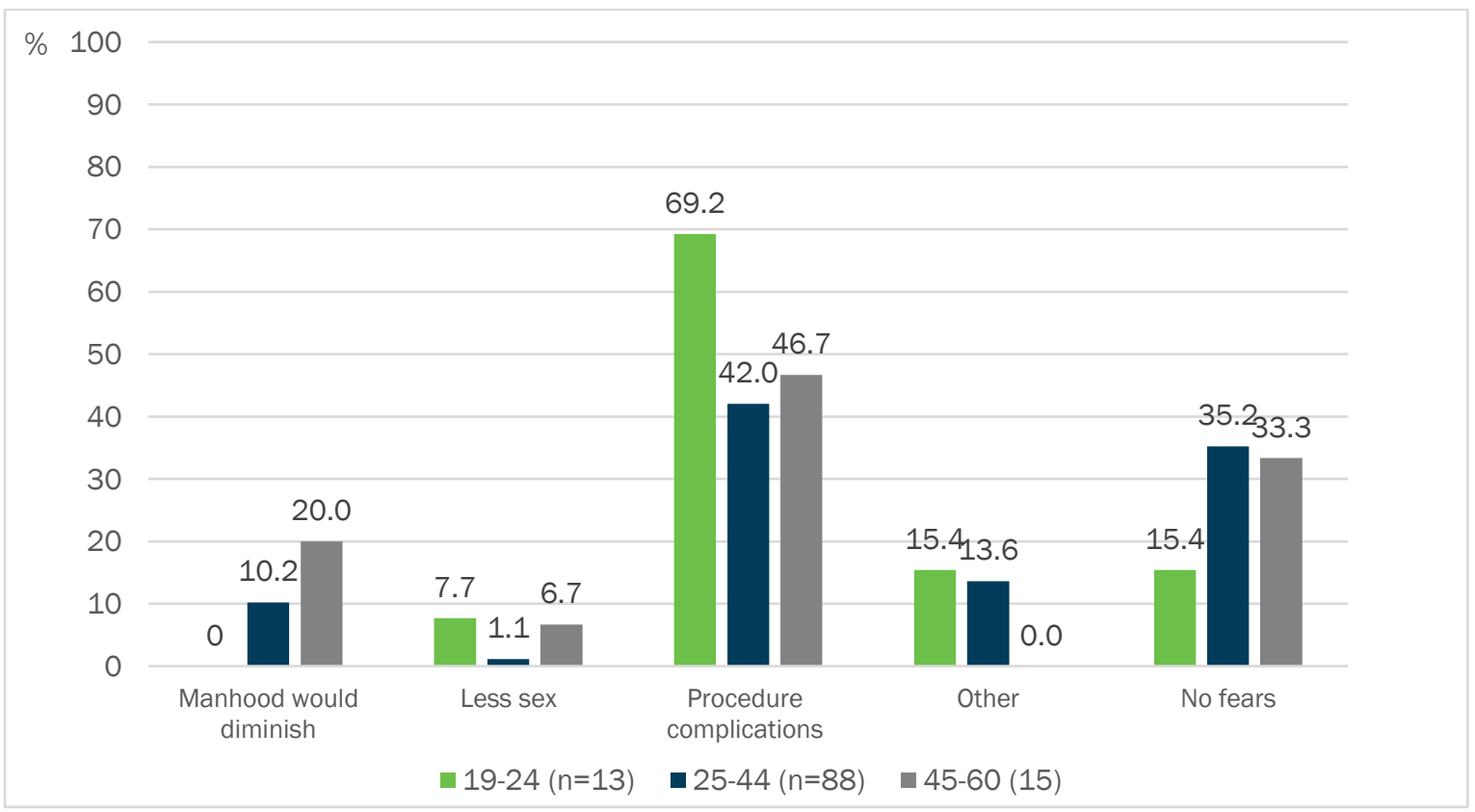




\section{Benefits you expect to obtain in your relationship after NSV}

One fourth of men surveyed expected an increase in sexual activity frequency (25\%) and improvements in their primary relationship (13.8\%). Twenty percent of those interviewed reported no expectation of changes after NSV.

\section{Understanding of self-care measures received after NSV}

Almost every man received instructions from clinic personnel immediately after NSV about subsequent self-care, as well as the need for a sperm count three months later. In the assessment of patients' understanding of these indications, 81.7 percent discussed hygiene and antiseptic measures for the wound, 52.9 percent mentioned waiting three to seven days to have sexual intercourse (without specification if a condom or other contraceptive protection was required), and 14.4 percent said that they must wait between 20 to 30 ejaculations before unprotected sex. The need to continue condom use to prevent STIs and a sperm count after three months were only mentioned spontaneously, for both, by less than four percent of respondents. 


\section{CONCLUSIONS AND RECOMMENDATIONS}

The men who elected to have NSV and agreed to participate in the survey during WVD in Mexico City are similar to those reported in other studies in urban settings: 19 to 60 years of age, with educations above the national average, in a stable relationship with at least two children, using contraception (mainly male condoms), and who chose NSV to avoid unwanted pregnancy, or already had a desired number of children, as the primary reason for vasectomy.

It is important to improve information campaigns, both in mass media and social networks, as well as through health services at all levels. The public should be aware of NSV as a permanent, simple, cost-effective method, with a low rate of complications and minimal pain.

The primary concern about NSV reported by men in this study related to complications or associated pain. Fears about changes in masculinity or sexual performance are also latent in this population, so a multidisciplinary team integrating counseling or psychological support should advise and support them in the vasectomy process.

Survey analysis shows that the decision to accept NSV was usually discussed with a relationship partner, with gynecologists as the principal providers who recommend the procedure, which reveals the need to incorporate $\mathrm{SRH}$ and male counseling, as well as encouraging urological integration, within RH and FP programs.

The health sector should consider expanding and promoting free campaigns for NSV, as well as routinely disseminating information throughout its institutions that offer it, to increase demand and reduce the unmet need reported by survey participants. Even though a service campaign does not reflect routine delivery, it is of utmost importance that NSV services place value on the clients' understanding of post-surgical and protective follow up measures (condom use and sperm count), as part of their care processes, to reduce risk of unwanted pregnancy in the months after NSV, as well as promoting condom use to avoid STIs.

Although the sample is small for statistical conclusions, it is interesting that young people between the ages of 19 and 25 without children chose NSV, with social and environmental awareness informing their decisions. This group also reported the highest barriers to obtaining NSV at the time of the survey, which is relevant because this group's interest was not guided by the WVD promotion campaign. The scope of national FP programs need to be expanded to guide and offer reversible or definitive methods to women and men who do not wish to have a family, or for those who already have their desired number of children.

It is recommended that SSA continue integrating NSV information, counseling, and services within the National FP Program and support follow up monitoring and evaluation of men who undergo NSV at least six months after the procedure, for better understanding of their post-NSV experience including method satisfaction and effects of their decision on their relationship partners. It would be beneficial for SSA to periodically assess the availability and quality of NSV services in Mexico's public and private sectors, and based upon this, continue to disseminate information on best practices for NSV provision-and influence NSV policies worldwide. 


\section{REFERENCES}

Bunce, A., G. Guest, H. Searing, V. Frajzyngier, P. Riwa, J. Kanama, I. Achwal. 2007. Factors affecting vasectomy acceptability in Tanzania. International Family Planning Perspectives 33: 13-21.

DOF. 2004. Resolución por la que se modifica la Norma Oficial Mexicana NOM-005-SSA2-1993, De los servicios de planificación familiar. México, Secretaría de Salud: Gobierno de la República.

Excélsior. 2017. En México, sólo 2\% de los hombres se practica la vasectomía: Ahued. www.excelsior.com.mx/comunidad/2017/11/19/1202263

García Moreno, J. and L.M. Solano Sainos. 2005. Aceptación y rechazo de vasectomía en hombres [Male acceptance or rejection of vasectomy]. Revista Médica del IMSS 43: 205-214.

INEGI. 2014. Encuesta Nacional de la Dinámica Demográfica 2014. www.beta.inegi.org.mx/proyectos/enchogares/especiales/enadid/2014

INEGI. 2015. Encuesta Intercensal 2015. www.beta.inegi.org.mx/proyectos/enchogares/especiales/intercensal

Jacobstein, R. 2015. The kindest cut: global need to increase vasectomy availability. Lancet Global Health 3(12): e733-e734.

Marvan, L., Y. Ehrenzweig, D. Hernandez- Aguilera. 2017. Mexican Men's View of Vasectomy. American Journal of Men's Health 11(3): 610-617.

Oliva Malagón, L., J.J. Hernández Garduño, M.M. Garduño Areizaga, L. Calzada Sánchez. 2011. Precedentes y efectos en la anticoncepción masculina sin bisturí [Precedents and effects of male contraception without a scalpel]. Colegio Mexicano de Urología Nacional 26: 14-17.

Pile, J.M. and M.A. Barone. 2009. Demographics of vasectomy-USA and international. Urologic Clinics of North America 36: 295-305. doi:10.1016/j.ucl.2009.05.006.

United Nations. 2017. World contraceptive use 2017. www.un.org/en/development/desa/population/publications/dataset/contraception/wcu2017.shtml

Secretaria de Salud. 2013. Programa de Acción Específico. Planificación Familiar y Anticoncepción 20132018. Gobierno de la República: México.

Secretaria de Salud. 2016. Impulsan equidad de género en materia de planificación familiar. Gobierno de la República. www.gob.mx/salud/prensa/impulsan-equidad-de-genero-en-materia-de-planificacion-familiar

World Vasectomy Day. 2017. Annual Report. 